\title{
Incidence of Mb2 in Maxillary Second Molars- A Cbct Analysis
}

\author{
Anjineyulu K² Anjaneyulu K1 \\ ${ }^{1}$ Saveetha Dental College and Hospitals, Saveetha Institute of Medical \\ and Technical Sciences (SIMATS), Saveetha University, Chennai,India. \\ ${ }^{2}$ Reader, Department of Conservative dentistry and Endodontics, \\ Saveetha Dental College and Hospitals, Saveetha Institute of Medical and \\ Technical Sciences (SIMATS), Saveetha University, Chennai,India.
}

\section{ABSTRACT}

The second mesiobuccal canal in mesiobuccal roots in maxillary molars is common. Failure on the location of these canals is associated with a high rate of unsuccessful treatments of maxillary molars. Therefore, the aim of the present study was to assess the incidence of MB2 in maxillary second molars. About 50 CBCT were obtained from the radiology department of Saveetha Dental College. Only 5 maxillary second molars presented with MB2 out of the 100 reports taken in the study (5.0\%). The incidence of MB2 in 17 was about (3.0\%) and (2.0\%) in 27; p=0.646 (>0.05) statistically not significant. When a root canal treatment fails, the clinician faces the challenge to make a decision that better solves the issue. Thorough knowledge is essential prior to initiation of endodontic therapy. The endodontist must accept the possibilities of extra canals for better management and a successful treatment outcome. Higher rate in the maxillary first molars when compared to the second molars. Previous studies demonstrated variations in classical triangular shaped access in maxillary molars might help the location of root canals.

\section{KEY WORDS: MB2, INCIDENCE RATES, MAXILLARY SECOND MOLARS.}

\section{INTRODUCTION}

Anatomical complexities impose limitations to the preparation of the root canal resulting in unsuccessful treatment. Such complexities are of great importance, especially in the maxillary molars (Christie, Peikoff and Fogel, 1991)(Fogel and Cunha, 2017)). These teeth present a great variety in the number of main canals located in many treatments. Particularly in the mesiobuccal roots,

\section{ARTICLE INFORMATION}

*Corresponding Author: Kanjaneyulu.sdc@saveetha.com Received 8th Aug 2020 Accepted after revision 19th Sep 2020 Print ISSN: 0974-6455 Online ISSN: 2321-4007 CODEN: BBRCBA

Thomson Reuters ISI Web of Science Clarivate Analytics USA and Crossref Indexed Journal

\section{Clarivate
Analytics}

NAAS Journal Score 2020 (4.31) SJIF: 2020 (7.728)

A Society of Science and Nature Publication,

Bhopal India 2020. All rights reserved.

Online Contents Available at: http//www.bbrc.in/

Doi: http://dx.doi.org/10.21786/bbrc/13.8/148 very often a canal might not be located such as the mesiolingual canal of the mesiobuccal root, mesiopalatal canal, or MB2 of the mesiobuccal root (Kulid and Peters, 1990). Knowledge of the morphology of the canal system, therefore is extremely important prior to planning an endodontic treatment, as its success relies on the location of all of the canals that can then be disinfected, shaped, and filled (Filho et al., 2009). In the past the periapical radiographs were the only tool to aid in the location of canals, currently the cone-beam computed tomography (CBCT) has become an important tool in this step.

CBCT is a 3D radio-graphic image that promotes images with more sensitivity and real anatomy (Nikoloudaki, Kontogiannis and Kerezoudis, 2015) . In addition, CBCT scans allow visualization of the images in axial, sagittal, and coronal views, aiding the detection of extra canals, anatomic variations, root resorptions and pathologies that might affect the hard tissues (Estrela et al., 2015)

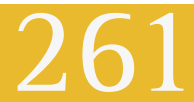


(Estrela et al., 2008). Undoubtedly, the dental operating microscopes with ultrasonic tips are considered the most helpful devices to locate extra canals (Coelhodecarvalho and Zuolo, 2000). Moreover, experience of the operator, along with the time employed in the search of MB2 canals along with certain specific tools is helpful in the clinical success of root canal location (Stropko, 1999).

The main aim of any endodontic treatment is to provide thorough mechanical and chemical cleansing of the pulp cavity and its complete obturation with an inert filling material ((Vertucci, 1984). One of the major failures in endodontic treatment is when treating maxillary molars is the inability to locate, debride, and fill the frequently present second mesiobuccal canal. Ingle stated that the frequent cause of endodontic failure is apical percolation and subsequent diffusion stasis into the root canal (Gerstein, 1983). Virtually all dentists thought that the mesiobuccal root (MBR) of maxillary molars are usually present with only one canal (Weine et al., 1969).

Concerning that, many papers have been published regarding the types of canal systems present in that root and their percentage. However, few studies have dealt exclusively with the canal configurations in the mesiobuccal roots of the maxillary second molar, possibly because of the assumption that the root is very similar to that of the maxillary first molar. Weine categorised four different types of configurations as follows: type I single canal from pulp chamber to apex; type II two canals leaving the chamber but merging shorter at the apex to form a single canal; type III two separate canals leaving the chamber and exiting the root in separate foramina; and type IV one canal leaving the chamber, but dividing short of the apex into two separate and distinct canals with separate foramina (Weine et al., 1969; Cohn, 2004).

The mesiobuccal root of the maxillary molars presents a flattening in the mesiodistal direction leading to the presence of a second canal in this root. The location of MB2 canal is paramount for the success of treatment in maxillary molars. Several clinical steps might assist the provider to locate the canal including the recognition of pulp chamber floor, magnification, ultrasonic tips, and dying, thereby enhancing the outcomes. However, its use is paramount for location of extra canals, including MB2 canals in the maxillary molars. Diamond coated tips can be used for the removal of dentin shelves located over the MB2 canals (Lambrianidis, 2017). A previous study showed that troughing the pulp chamber floor up to $2 \mathrm{~mm}$ from the palatal to the mesiobuccal canal is helpful in locating the MB2 canals (Parker et al., 2017). During irrigation procedures with sodium hypochlorite, the clinician is able to observe bubble formation. These bubbles might indicate the possible location of the root canal entrance. While the location of the MB2 canals is a challenging situation, the preparation of these canals is not less difficult.

We have numerous highly cited publications on well designed clinical trials and lab studies (Govindaraju,
Neelakantan and Gutmann, 2017; Azeem and Sureshbabu, 2018; Jenarthanan and Subbarao, 2018; Manohar and Sharma, 2018; Nandakumar and Nasim, 2018; Teja, Ramesh and Priya, 2018; Janani and Sandhya, 2019; Khandelwal and Palanivelu, 2019; Malli Sureshbabu et al., 2019; Poorni, Srinivasan and Nivedhitha, 2019; Rajakeerthi and Ms, 2019; Rajendran et al., 2019; Ramarao and Sathyanarayanan, 2019; Siddique and Nivedhitha, 2019; Siddique et al., 2019; Siddique, Nivedhitha and Jacob, 2019). This has provided the right platforms for us to pursue the current study. Our aim is to assess the incidence of MB2 in maxillary second molars in the current study by means of a literature review, followed by observed clinical cases, the importance of the location of mesiobuccal canals in the maxillary second molars.

\section{MATERIAL AND METHODS}

In the current study, a total of 50 CBCT scan reports were collected from the Radiology department of Saveetha Dental College, Chennai. The CBCT scans were analysed for the incidence of MB2 in the mesiobuccal roots of the maxillary second molars. Dependent variables in the study were the maxillary second molars, number of MB2 in each mesiobuccal root. Independent variables were the name, age, gender of the study samples. The data collected were cross verified by another examiner. The collected results were entered in Microsoft excel. And the data analysis was done using SPSS software version 20.0. Statistics used for analysis in the study were descriptive statistics and comparison of variables were done using chi square test where $p<0.05$, which is statistically significant.

\section{RESULT AND DISCUSSION}

The operator must look for the additional canals prior to any treatment (Orafi and Hammad, 2017). It is important for the clinician to have a strong conviction about the MB2 system in all maxillary molars. In conjunction with dental operating microscopes, rhomboid access and the use of specific instruments and other aids can occasionally be used to enhance the visualization of MB2 systems (Seidberg et al., 1973). It is of great interest to note that the studies utilizing microscopes have reported a significantly higher percentage of MB2 canal system occurrences than the other studies. To treat maxillary second molars efficiently, an understanding of the morphology of the mesiobuccal canal system is most mandatory. Initially the canal in the MBR is the shape of a kidney bean. With continued deposition of secondary dentin, the isthmus between the poles becomes narrow and eventually may even close resulting in two canals. It will eventually close off leaving a small space, which makes it more difficult to locate. Therefore, depending on the age of the tooth, the MBR may have a variety of configurations (Bhuyan et al., 2014) .

Out of which 100 maxillary second molars which were reviewed for the incidence of MB2. Only 5 maxillary second molars presented with MB2 out of the overall 100 
reports taken in the present study (Figure 1). Thereby, the incidence of MB2 in maxillary second molars was found to be 5.0\% (Figure 2). The incidence of MB2 in 17 was about (3.0\%) and (2.0\%) in 27. Whereas, (47.0\%) was absent in 17and (48.0\%) was absent in 27 (Figure 3) $\mathrm{p}=0.646(>0.05)$ statistically not significant. Reis et al, pointed to age as a factor that impacts the visualization of MB2 canals (Reis et al., 2013). In that study, patients of 20 to 30 years had their canals visual-ized in 90.7\% of the cases, while patients with ages ranging from 60 to 70 years had their canals visible in $81.9 \%$ of the cases. Another study assessed root canal morphology using CBCT scans pointed out that full crown coverage is another factor that can prevent the location of MB2 canals (Studebaker et al., 2018).

Figure 1: CBCT image depicting the incidence of MB2 in the maxillary second molars 17 (A) (B) and 27(C) taken in the present study.

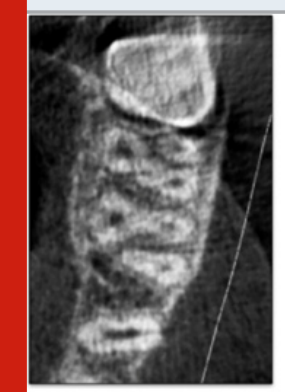

(A)

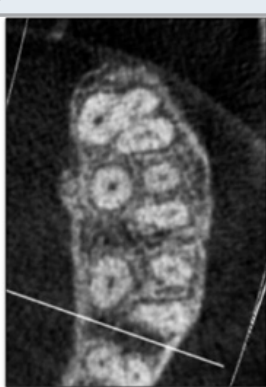

(B)

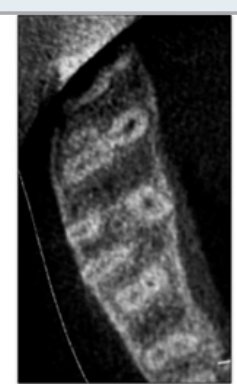

(C)
Figure 2: Bar chart depicting the incidence of MB2 in the maxillary second molars. From the results of this graph it is evident that only in 5\% of the cases MB2 canal was present (blue) in the maxillary second molars. And in 95\% of the cases MB2 canal was absent (red).

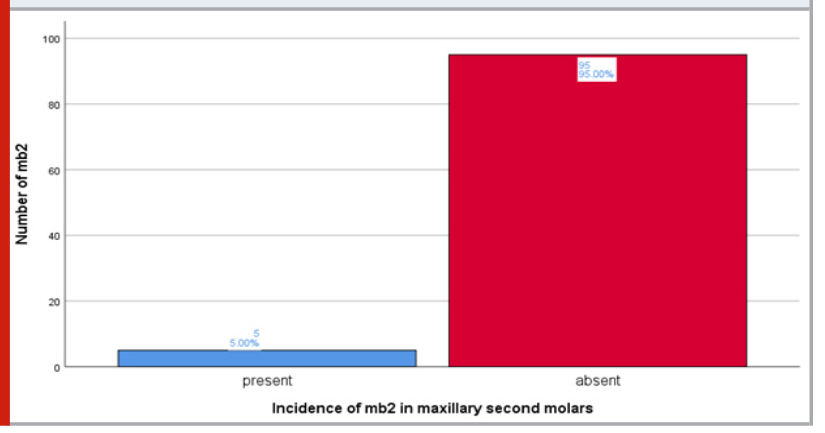

Medication is another factor that impacts root canal location. A variety of methods have been introduced to the study canal configurations, investigations from 1972 to 1984 reported the occurrence of two canals in the MBR of the maxillary second molar were found in the range between 12\% to 38\% (Vertucci, 1984). Kulild and Peters found that 14 to 32 teeth (43.8\%) had two canals in the mesiobuccal root of the maxillary second molar, when files were placed in the orifices and examined radio graphically (Kulid and Peters, 1990). The number of two canals increased to 25 to $32(78.2 \%)$ when the orifices were countersunk with a bur before files were placed into the canals. Finally, 30 of the 32 teeth (93.7\%) had two canals when the roots were sectioned horizontally and examined histologically (Eskoz and Weine, 1995).

Figure 3: Bar chart depicting the association between the incidence of MB2 canal in maxillary second molars and the teeth number. Blue denotes 17 and red denotes 27 . The incidence of MB2 in 17 was about (3.0\%) and (2.0\%) in 27. Whereas, $(47.0 \%)$ was absent in 17 and (48.0\%) was absent in 27. Pearson's Chi Square test value $=0.211$; $\mathrm{df}=1 ; \mathrm{p}=0.646(>0.05)$ statistically not significant.

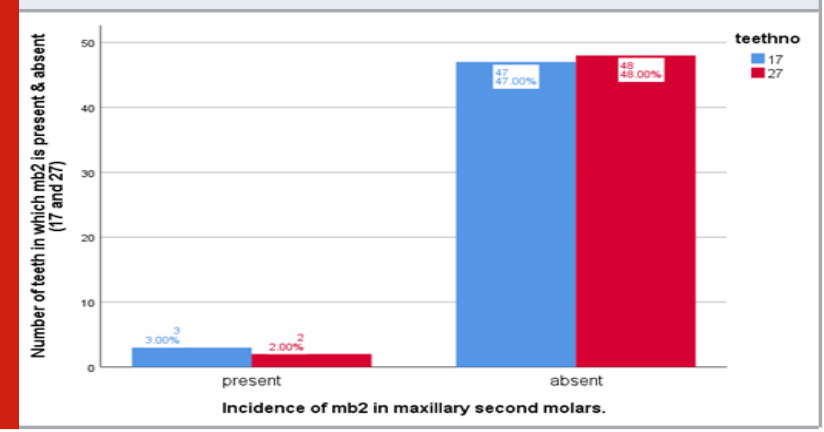

Several methods have been respirated to help locate the extra canals. Foremost a modification of the access preparation to a rhomboidal shape for the maxillary molars as compared to the classical triangular outline ((Versiani, Basrani and Sousa-Neto, 2018). This provides better visibility and accessibility. Thorough probing of the fissure or the groove between the main canal was previously proposed in order to locate the orifice of another canal. This fissure or groove must be deepened to remove any projections that might conceal the opening of canals. A troughing process must be accomplished with burs or ultrasonic instruments if the MB2 orifice is not easily identified. The MB2 orifice are usually found mesial to an imaginary line between the MB1 and palatal orifices, and commonly, about $2-3 \mathrm{~mm}$ palatal to the MB1 orifice.

The MB2 canal can be challenging to locate most of the time. However, the MB2 canal often has a marked mesial inclination apical to its orifice in the coronal 1 to $3 \mathrm{~mm}$, so when an attempt is made to instrument the MB2, the tip of file catches against the mesial wall of canal, further preventing apical progress. Since the MB2 canal is smaller and usually more calcified than MB1, the problem is exacerbated. After locating MB2, inclining the dental or ultrasonic handpiece to the distal, as far as the access preparation permit or allows the first few millimeters of this overlying roof of calcified tissue to be safely removed. After this refinement of access cavity preparation, a more desired straight line access can be achieved. To facilitate location and instrumentation of the MB2 canal, the access has to be rhomboidal in shape to allow the management of the MB2 canal (Stropko, 1999).

\section{CONCLUSION}

From the present study about 5.0\% was the incidence 
rate of MB2 in the maxillary second molars. It can be concluded that the proper location and treatment of MB2 canals are essential for the success of treatment of the maxillary molars. The clinician should be able to locate and manage the cases in primary treatments and also choose the best option when the initial treatment fails. Besides the anatomy, use of dental operating microscopes, and management of CBCT images must be the minimum competencies of a competent endodontist.

\section{ACKNOWLEDGEMENTS}

I would sincerely thank my guide, Department of Conservative Dentistry and Endodontics, Radiology department Saveetha Dental College and Hospitals, Saveetha institute Medical and Technical Sciences (SIMATS), Saveetha University for helping me complete the research work.

Conflict of Interest: The authors declare that there were no conflicts of interest in the present study.

\section{REFERENCES}

Azeem, R. A. and Sureshbabu, N. M. (2018) 'Clinical performance of direct versus indirect composite restorations in posterior teeth: A systematic review', Journal of conservative dentistry: JCD, 21(1), pp. 2-9. Bhuyan, A. et al. (2014) 'Root canal configuration of permanent maxillary first molar in Khasi population of Meghalaya: An in vitro study', Journal of Conservative Dentistry, p. 359. doi: 10.4103/0972-0707.136511.

Christie, W. H., Peikoff, M. D. and Fogel, H. M. (1991) 'Maxillary molars with two palatal roots: A retrospective clinical study', Journal of Endodontics, pp. 80-84. doi: 10.1016/s0099-2399(06)81613-4.

Coelho De Carvalho, M. and Zuolo, M. (2000) 'Orifice Locating with a Microscope', Journal of Endodontics, pp. 532-534. doi: 10.1097/00004770-20000900000012.

Cohn, S. A. (2004) 'Endodontic Therapy 6th Edition:By Franklin S. Weine', Australian Endodontic Journal, pp. 33-33. doi: 10.1111/j.1747-4477.2004.tb00168.x.

Eskoz, N. and Weine, F. S. (1995) 'Canal configuration of the mesiobuccal root of the maxillary second molar', Journal of Endodontics, pp. 38-42. doi: 10.1016/s00992399(06)80555-8.

Estrela, C. et al. (2008) 'Accuracy of Cone Beam Computed Tomography and Panoramic and Periapical Radiography for Detection of Apical Periodontitis', Journal of Endodontics, pp. 273-279. doi: 10.1016/j. joen.2007.11.023.

Estrela, C. et al. (2015) 'Frequency of Root Canal Isthmi in Human Permanent Teeth Determined by Cone-beam Computed Tomography', Journal of Endodontics, pp. 1535-1539. doi: 10.1016/j.joen.2015.05.016.

Filho, F. B. et al. (2009) 'Analysis of the Internal Anatomy of Maxillary First Molars by Using Different Methods', Journal of Endodontics, pp. 337-342. doi: 10.1016/j.joen.2008.11.022.

Fogel, H. M. and Cunha, R. S. (2017) 'Maxillary First Molars with 2 Distobuccal Canals: A Case Series', Journal of Endodontics, pp. 1925-1928. doi: 10.1016/j. joen.2017.07.004.

Gerstein, H. (1983) Techniques in Clinical Endodontics. W.B. Saunders Company.

Govindaraju, L., Neelakantan, P. and Gutmann, J. L. (2017) 'Effect of root canal irrigating solutions on the compressive strength of tricalcium silicate cements', Clinical oral investigations, 21(2), pp. 567-571.

Janani, K. and Sandhya, R. (2019) 'A survey on skills for cone beam computed tomography interpretation among endodontists for endodontic treatment procedure', Indian journal of dental research: official publication of Indian Society for Dental Research, 30(6), pp. 834-838.

Jenarthanan, S. and Subbarao, C. (2018) 'Comparative evaluation of the efficacy of diclofenac sodium administered using different delivery routes in the management of endodontic pain: A randomized controlled clinical trial', Journal of conservative dentistry: JCD, 21(3), pp. 297-301.

Khandelwal, A. and Palanivelu, A. (2019) 'Correlation Between Dental Caries And Salivary Albumin In Adult Population In Chennai: An In Vivo Study', Brazilian Dental Science, 22(2), pp. 228-233.

Kulid, J. C. and Peters, D. D. (1990) 'Incidence and configuration of canal systems in the mesiobuccal root of Maxillary first and second molars', Journal of Endodontics, pp. 311-317. doi: 10.1016/s00992399(06)81940-0.

Lambrianidis, T. (2017) Management of Fractured Endodontic Instruments: A Clinical Guide. Springer. Malli Sureshbabu, N. et al. (2019) 'Concentrated Growth Factors as an Ingenious Biomaterial in Regeneration of Bony Defects after Periapical Surgery: A Report of Two Cases', Case reports in dentistry, 2019, p. 7046203.

Manohar, M. P. and Sharma, S. (2018) 'A survey of the knowledge, attitude, and awareness about the principal choice of intracanal medicaments among the general dental practitioners and nonendodontic specialists', Indian journal of dental research: official publication of Indian Society for Dental Research, 29(6), pp. 716-720.

Nandakumar, M. and Nasim, I. (2018) 'Comparative evaluation of grape seed and cranberry extracts in preventing enamel erosion: An optical emission spectrometric analysis', Journal of conservative dentistry: JCD, 21(5), pp. 516-520.

Nikoloudaki, G. E., Kontogiannis, T. G. and Kerezoudis, N. P. (2015) 'Evaluation of the Root and Canal Morphology of Maxillary Permanent Molars and the Incidence of the Second Mesiobuccal Root Canal in Greek Population Using Cone-beam Computed Tomography', The Open Dentistry Journal, pp. 267-272. doi: 10.2174/1874210601509010267. 
Orafi, I. and Hammad, M. (2017) 'Effects of Horizontal Beam Angulations and Imaging System on the Identification of the MB2 of Maxillary First Molar: An ROC Analysis', Open Journal of Dentistry and Oral Medicine, pp. 85-89. doi: 10.13189/ojdom.2017.050403.

Parker, J. et al. (2017) 'CBCT uses in clinical endodontics: the effect of CBCT on the ability to locate MB2 canals in maxillary molars', International Endodontic Journal, pp. 1109-1115. doi: 10.1111/iej.12736.

Poorni, S., Srinivasan, M. R. and Nivedhitha, M. S. (2019) 'Probiotic strains in caries prevention: A systematic review', Journal of conservative dentistry: JCD, 22(2), pp. 123-128.

Raja Keerthi, R. and Ms., N. (2019) 'Natural Product as the Storage medium for an avulsed tooth - A Systematic Review', Cumhuriyet Dental Journal, 22(2), pp. 249-256.

Rajendran, R. et al. (2019) 'Comparative Evaluation of Remineralizing Potential of a Paste Containing Bioactive Glass and a Topical Cream Containing Casein Phosphopeptide-Amorphous Calcium Phosphate: An in Vitro Study', Pesquisa brasileira em odontopediatria e clinica integrada, 19(1), pp. 1-10.

Ramarao, S. and Sathyanarayanan, U. (2019) 'CRA Grid - A preliminary development and calibration of a paper-based objectivization of caries risk assessment in undergraduate dental education', Journal of conservative dentistry: JCD, 22(2), pp. 185-190.

Reis, A. G. de A. R. et al. (2013) 'Second Canal in Mesiobuccal Root of Maxillary Molars Is Correlated with Root Third and Patient Age: A Cone-beam Computed Tomographic Study', Journal of Endodontics, pp. 588-592. doi: 10.1016/j.joen.2013.01.003.

Seidberg, B. H. et al. (1973) 'Frequency of Two Mesiobuccal Root Canals in Maxillary Permanent First Molars', The Journal of the American Dental Association, pp. 852-856. doi: 10.14219/jada.archive.1973.0489.

Siddique, R. et al. (2019) 'Qualitative and quantitative analysis of precipitate formation following interaction of chlorhexidine with sodium hypochlorite, neem, and tulsi', Journal of conservative dentistry: JCD, 22(1), pp. 40-47.

Siddique, R. and Nivedhitha, M. S. (2019) 'Effectiveness of rotary and reciprocating systems on microbial reduction: A systematic review', Journal of conservative dentistry: JCD, 22(2), pp. 114-122.

Siddique, R., Nivedhitha, M. S. and Jacob, B. (2019) 'Quantitative analysis for detection of toxic elements in various irrigants, their combination (precipitate), and para-chloroaniline: An inductively coupled plasma mass spectrometry study', Journal of conservative dentistry: JCD, 22(4), pp. 344-350.

Stropko, J. J. (1999) 'Canal morphology of maxillary molars: Clinical observations of canal configurations', Journal of Endodontics, pp. 446-450. doi: 10.1016/ s0099-2399(99)80276-3.

Studebaker, B. et al. (2018) 'The Incidence of Second Mesiobuccal Canals Located in Maxillary Molars with the Aid of Cone-beam Computed Tomography', Journal of Endodontics, pp. 565-570. doi: 10.1016/j. joen.2017.08.026.

Teja, K. V., Ramesh, S. and Priya, V. (2018) 'Regulation of matrix metalloproteinase-3 gene expression in inflammation: A molecular study', Journal of conservative dentistry: JCD, 21(6), pp. 592-596.

Versiani, M. A., Basrani, B. and Sousa-Neto, M. D. (2018) The Root Canal Anatomy in Permanent Dentition. Springer.

Vertucci, F. J. (1984) 'Root canal anatomy of the human permanent teeth', Oral surgery, oral medicine, and oral pathology, 58(5), pp. 589-599.

Weine, F. S. et al. (1969) 'Canal configuration in the mesiobuccal root of the maxillary first molar and its endodontic significance', Oral Surgery, Oral Medicine, Oral Pathology, pp. 419-425. doi: 10.1016/00304220(69)90237-0. 